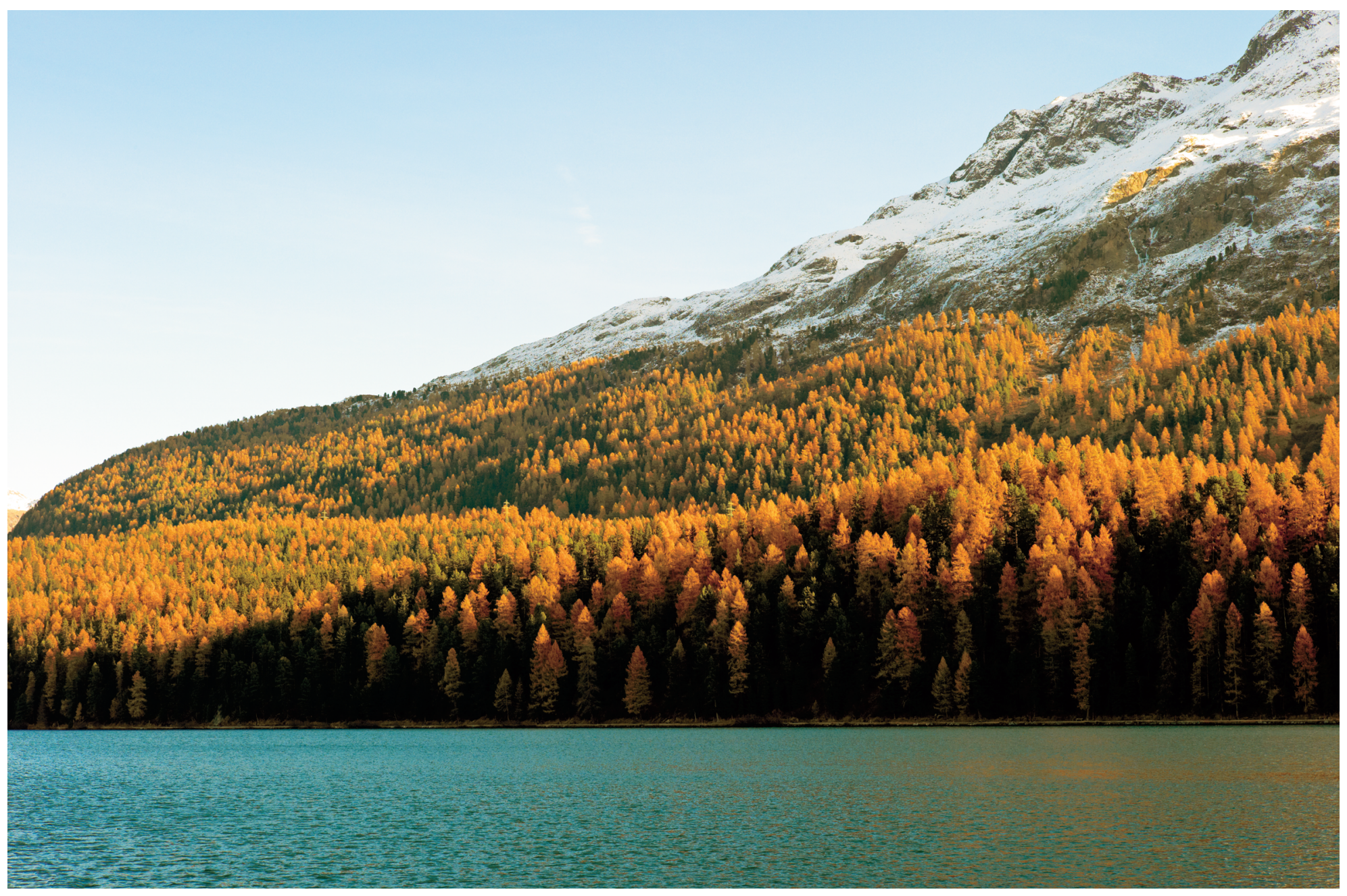

\title{
St. Moritz
}

Graubünden / Grigioni / Grischun

Schweiz / Suisse / Svizzera / Svizra

\section{BIRKHÄUSER}


Fotoessay Hartmut Nägele

437 Projekte / 37 Progetti / 37 Projects

Loredana Ponticell

37 IT

"Wehlsch pirg"

$\rightarrow \mathrm{D} 382 / \rightarrow \mathrm{E} 383$

Köbi Gantenbein

$61 \mathrm{CH}$

Wohnen in den Alpen. Eine biografische Notiz

$\rightarrow \mid 385 / \rightarrow E 387$

Christian Schittich

93 DE

Der deutsche Alpenraum: Ein paar

Vorberge, aber keine signifikante Architektur

$\rightarrow \mid 389 / \rightarrow E 390$

Hansjörg Hilti

117 LI

Wohnraum Alpen

$\rightarrow \mid 391 / \rightarrow E 393$

D

Wojciech Czaja

133 AT

Lederhose war gestern

$\rightarrow \mid 394 / \rightarrow$ E 396

246 Vorwort

Luigi Scolari / Georg Klotzner

Miha Dešman

258 Mehr Baukultur

181 SI

Prebivališče Alpe Postajamo normalni?

$\rightarrow \mathrm{D} 397 / \rightarrow 1400 / \rightarrow \mathrm{E} 402$

264 Wohn Raum Alpen

Eva Herrmann, Markus Kuntsche

Axel Sowa

221 FR

Avoriaz et le Queyras -

Deux modèles d'aménagement dans

les Alpes françaises

$\rightarrow$ D 404/ $\rightarrow 1407 / \rightarrow$ E 409

272 Eine besondere Identität:

die Entwicklung der Raumplanung in Südtirol

Luigi Scolari

286 Wohnen in den Alpen

Paolo Mazzoleni

294100 Jahre Wohnbau in Südtirol Wolfgang Piller

30537 Projekte

Beschreibung 
I

Italiano

247 Introduzione

Luigi Scolari / Georg Klotzner

260 Più cultura edilizia

Peter Ebner

268 Abitare le Alpi

Eva Herrmann, Markus Kuntscher

277 Un caso particolare: l'identità dell'urbanistica in Alto Adige Luigi Scolari

289 Abitare nelle Alpi Paolo Mazzoleni

297100 anni di edilizia residenziale in Alto Adige Wolfgang Piller

\section{Progetti}

Descrizione
$\mathbf{E}$

English

248 Introduction

Luigi Scolari / Georg Klotzner

262 More Building Culture

Peter Ebner

270 Living in the Alps

Eva Herrmann, Markus Kuntscher

282 The Special Characteristics of Development Planning in the Alto Adige Luigi Scolari

292 Housing in the Alps Paolo Mazzoleni

301 A Hundred Years of Housing in the Alto Adige Wolfgang Piller

30537 Projects 